University of Nebraska - Lincoln

DigitalCommons@University of Nebraska - Lincoln

June 2006

\title{
Mouse models for assessing the role of selenoproteins in health and development
}

\author{
Bradley A. Carlson \\ National Cancer Institute, National Institutes of Health, Bethesda, MD \\ Xue-Ming Xu \\ National Cancer Institute, National Institutes of Health, Bethesda, MD \\ Rajeev Shrimali \\ National Cancer Institute, National Institutes of Health, Bethesda, MD \\ Aniruddha Sengupta \\ National Cancer Institute, National Institutes of Health, Bethesda, MD \\ Min-Hyuk Yoo \\ National Cancer Institute, National Institutes of Health, Bethesda, MD
}

See next page for additional authors

Follow this and additional works at: https://digitalcommons.unl.edu/biochemgladyshev

Part of the Biochemistry, Biophysics, and Structural Biology Commons

Carlson, Bradley A.; Xu, Xue-Ming; Shrimali, Rajeev; Sengupta, Aniruddha; Yoo, Min-Hyuk; Zhong, Nianxin; Hatfield, Dolph L.; Irons, Robert; Davis, Cindy D.; Lee, Byeong Jae; Novoselov, Sergey V.; and Gladyshev, Vadim N., "Mouse models for assessing the role of selenoproteins in health and development" (2006). Vadim Gladyshev Publications. 37.

https://digitalcommons.unl.edu/biochemgladyshev/37

This Article is brought to you for free and open access by the Biochemistry, Department of at DigitalCommons@University of Nebraska - Lincoln. It has been accepted for inclusion in Vadim Gladyshev Publications by an authorized administrator of DigitalCommons@University of Nebraska - Lincoln. 


\section{Authors}

Bradley A. Carlson, Xue-Ming Xu, Rajeev Shrimali, Aniruddha Sengupta, Min-Hyuk Yoo, Nianxin Zhong, Dolph L. Hatfield, Robert Irons, Cindy D. Davis, Byeong Jae Lee, Sergey V. Novoselov, and Vadim N. Gladyshev 


\title{
SELENIUM \\ Its Molecular Biology and Role in Human Health, Second Edition
}

Edited by

\author{
Dolph L. Hatfield \\ National Cancer Institute, USA \\ Marla J. Berry \\ University of Hawaii, USA \\ and \\ Vadim N. Gladyshev \\ University of Nebraska, USA
}

黛 ${ }_{2006}^{\text {Springer }}$ 


\section{Chapter 29. Mouse models for assessing the role of selenoproteins in health and development}

Bradley A. Carlson, Xue-Ming Xu, Rajeev Shrimali, Aniruddha Sengupta, Min-Hyuk Yoo, Nianxin Zhong and Dolph L. Hatfield

Molecular Biology of Selenium Section, Laboratory of Cancer Prevention, Center for Cancer Research, National Cancer Institute, National Institutes of Health, Bethesda, MD 20892, USA

Robert Irons ${ }^{1}$ and Cindy D. Davis

Nutritional Science Research Group, Division of Cancer Prevention, National Cancer Institute, National Institutes of Health, Bethesda, MD 20892, USA

Byeong Jae Lee

Laboratory of Molecular Genetics, Institute of Molecular Biology and Genetics, School of Biological Sciences, Seoul National University, Seoul 151-742, Korea

Sergey V. Novoselov and Vadim N. Gladyshev

Department of Biochemistry, University of Nebraska, Lincoln, NE 68688, USA

Summary: Mouse models have been generated to assess the roles of selenoproteins involved with housekeeping tasks and/or stress-related phenomena in development and health. Each mouse model has taken advantage of the fact that the synthesis of all selenoproteins is dependent on the expression of two selenocysteine (Sec) $\mathrm{tRNA}^{[\mathrm{Ser}] \mathrm{Sec}}$ isoforms that differ from each other by a single methyl group on the ribosyl moiety at position 34 . The endogenous Sec tRNA ${ }^{[\mathrm{Ser}] \mathrm{Ssc}}$ population was selectively altered by generating mouse models involving 1) transgenic animals carrying mutant or wild type Sec tRNA $^{[\mathrm{Ser}] \mathrm{Sec}}$ transgenes, 2) conditional knockout animals carrying a floxed Sec tRNA ${ }^{[\mathrm{Ser}] \mathrm{Sec}}$ gene that was targeted for removal in specific tissues and organs using loxP-Cre technology and 3) transgenic/standard knockout animals carrying mutant or wild type transgenes and a knockout of the Sec $\mathrm{tRNA}^{[\mathrm{Ser}] \mathrm{Sec}}$ gene wherein the animal's survival is dependent on the transgene. These mouse models perturbed selenoprotein expression, often in a protein- and tissue-specific manner, permitting us to better assess their function in health and development.

${ }^{T} \mathrm{RI}$ is also affiliated with the Molecular Biology of Selenium Section, Laboratory of Cancer Prevention, CCR, NCI, NIH, Bethesda, MD 20892. 


\section{Introduction}

Numerous human clinical trials examining the role of selenium in health have been initiated recently, or have already been completed. Perhaps the most famous of those studies that have been completed is that of Clark et al [1]. These investigators reported in 1996 that supplementing the diet with 200 micrograms of selenium/day reduced the incidence of prostate and colon cancers by more than $50 \%$ and lung cancer by about $35 \%$. This study provided the basis for numerous subsequent human clinical trials involving selenium. For example, the largest human clinical trial ever undertaken, the Selenium and Vitamin E Cancer Prevention Trial (SELECT [2]), involves more than 35,000 males in determining whether selenium and vitamin $\mathrm{E}$ may play a role in protecting men against prostate cancer. Another human clinical trial recently undertaken involves 1960 individuals in determining whether selenium may have a role in preventing the occurrence of secondary lung tumors in patients with a previous surgically removed non-small cell lung lesion [3]. These trials are being carried out at the cost of hundreds of millions of dollars with little or no understanding of how selenium acts metabolically to bring about potential health benefits. It is important therefore to generate mouse models to determine how selenium acts at the molecular level in promoting better health and to determine whether small molecular weight selenocompounds and/or selenoproteins are the responsible agents.

Selenoproteins are dependent on Sec $t \mathrm{RNA}^{[\mathrm{Ser}] \mathrm{Sec}}$ for their expression as discussed in detail in Chapter 3 (see also [4,5]). In addition, the Sec $\mathrm{tRNA}^{[\mathrm{Ser}] \mathrm{Sec}}$ population in mammalian cells is composed of two major isoforms that differ from each other by a 2'-O-methylribosyl moiety at position 34 which is designated Um34 (Chapter 3 and [4,5]). The two isoforms, designated $\mathrm{mcm}^{5} \mathrm{U}$ and $\mathrm{mcm}^{5} \mathrm{Um}$, have different roles in selenoprotein synthesis wherein $\mathrm{mcm}^{5} \mathrm{U}$ appears to be largely responsible for the expression of housekeeping selenoproteins and $\mathrm{mcm}^{5} \mathrm{Um}$ largely responsible for selenoproteins involved in stress-related phenomena [6,7].

By perturbing the expression of Sec tRNA ${ }^{[\mathrm{Ser}] \mathrm{Sec}}$ in mice, selenoprotein synthesis can be altered in such a way that their roles in development and health can be readily studied. In fact, Sec tRNA ${ }^{[\text {[Ser]Sec }}$ synthesis can be modulated in various ways in generating different mouse lines so that the roles of selenoproteins involved in housekeeping tasks and in stress-related phenomena can be elucidated. We have generated several mouse models for examining the role of selenoproteins in development and health. These mouse models involve generating transgenic, standard knockout, conditional knockout or a combination of transgenic/knockout mice encoding either wild type or a mutant Sec tRNA ${ }^{[\mathrm{Ser}] \mathrm{Sec}}$ gene or transgene. It should also be noted that the characteristics and properties of a number of individual selenoproteins have been examined, including being targeted for removal, to 
assess their roles in health and development (see the Chapters in Part II. Selenium-containing proteins).

\section{Mouse models for elucidating the role of selenoproteins in development and health}

To generate mouse models for elucidating selenoprotein function, we took advantage of the fact that selenoprotein synthesis is dependent on the presence of Sec tRNA ${ }^{[\mathrm{Ser}] \mathrm{Sec}}$. Our mouse models involve the introduction of a transgene, designated $t r s p^{t}$, or manipulation of the Sec tRNA ${ }^{[\mathrm{Ser}] \mathrm{Sec}}$ gene, designated trsp and they are summarized as follows: 1) transgenic mice carrying wild type or a mutant $t r s p^{t}[8]$; 2) conditional knockout mice carrying a floxed trsp that can be specifically targeted for removal using loxP-Cre technology [9]; and 3) standard knockout/transgenic mice containing trsp knockout, designated $\Delta$ trsp, and carrying wild type or mutant trsp transgenes in which the survival of the animal is dependent on the transgene [6,7]. A fourth mouse model is also briefly discussed wherein transgenic/conditional knockout mice carrying two transgenes, a Cre transgene under control of a promoter targeted for a specific organ or tissue, and a wild type or mutant $t r s p^{t}$ in addition to the targeted (floxed) trsp (B.A. Carlson, M.E. Moustafa, R. Shrimali, M. Rao, N. Zhong, S. Wang, L. Feigenbaum, B.J. Lee, V.N. Gladyshev and D.L. Hatfield, submitted). The mouse models are shown in Table 1 . They were prepared for assessing the roles of selenoproteins in health and development as well as defining the roles of the two Sec tRNA ${ }^{[\operatorname{Ser}] \mathrm{Sec}}$ isoforms, $\mathrm{mcm}^{5} \mathrm{U}$ and $\mathrm{mcm}^{5} \mathrm{Um}$, in selenoprotein synthesis. Since the role of $\mathrm{mcm}^{5} \mathrm{U}$, which is largely involved in the expression of housekeeping selenoproteins, and of $\mathrm{mcm}^{5} \mathrm{Um}$, which is largely involved in the expression of selenoproteins involved in stress-related phenomena, has been discussed in Chapter 3 and detailed elsewhere [5-7], the emphasis of the present chapter is on generating mouse models for examining the roles of selenoproteins in health and development. It should be noted that some of our mouse models may also be used to elucidate the role of small molecular weight selenocompounds in disease prevention.

\section{Transgenic mouse models}

Transgenic mice are generated by introducing one or more copies of the wild type or mutant trsp into the mouse genome. The resulting mice are then bred to obtain a stable breeding population (i.e., mice that are homozygous for the transgene). Mutations were made at either position 37 [8] or at postion 34 in Sec tRNA ${ }^{[\mathrm{Ser}] \mathrm{Sec}}$ for preparing mutant transgenes. The base at position 37 in the fully maturated $\operatorname{tRNA}{ }^{[\mathrm{Ser}] \mathrm{Sec}}$ is isopentenyladenosine $\left({ }^{6} \mathrm{~A}\right)$, while that at position 34 is $\mathrm{mcm}^{5} U$ (see Chapter 3 or $[4,5]$ ). The base at position 37 was changed to $G$ (A37->G37) and that at position 34 to $A$ (T34->A34). Importantly, neither of these two, very different, mutant tRNAs contain 
Um34, the methyl group located at the 2'-hydroxylribose on $\mathrm{mcm}^{5} \mathrm{U}$ [10]. An $\mathrm{A}$ in the wobble position of the anticodon in any tRNA is normally converted to I. About $65 \%$ of the A34 mutant Sec tRNA ${ }^{[\mathrm{Ser}] \mathrm{Sec}}$ is converted to I34 in mouse liver (B.A. Carlson, M.E. Moustafa, R. Shrimali, M. Rao, N. Zhong, S. Wang, L. Feigenbaum, B.J. Lee, V.N. Gladyshev and D.L. Hatfield, submitted), and interestingly, the ACA and ICA anticodons in A34 Sec tRNA ${ }^{[\mathrm{Ser}] \mathrm{Sec}}$ decode UGU and UGU, UGC (UGU and UGC are codons for cysteine) and UGA (UGA is the codon for Sec), respectively.

Table 1. Mouse models and their uses.

\begin{tabular}{|c|c|c|}
\hline Type & Genotype $^{a}$ & Uses $^{b}$ \\
\hline Transgenic & $t r s p^{t}$ & $\begin{array}{l}\text { Determine if Sec tRNA } \\
\text { limiting [8] }[8] \text { isec } \\
\mathrm{SP}^{c} \text { rescue in standard } \mathrm{KO}^{d}[6,7] \\
\mathrm{SP}^{c} \text { replacement in targeted tissues } \\
\text { and organs }\end{array}$ \\
\hline Transgenic & $\mathrm{G} 37 t r s p^{t}$ & $\begin{array}{l}\text { Rescue of } \mathrm{SPs}^{c} \text { in } \mathrm{KO}^{d} \text { mice } \\
\text { Replacement of SPs in conditional } \\
\mathrm{KO}^{d} \text { mice } \\
\text { Roles in muscle adaptation [9] and } \\
\text { cancer risk in prostate, }{ }^{e} \text { mammary } \\
\text { gland and colon }\end{array}$ \\
\hline Transgenic & $\mathrm{A} 34 \operatorname{trsp}^{t}$ & $\mathrm{SP}^{c}$ replacement only \\
\hline Standard $\mathrm{KO}^{d}$ & $\widehat{\Delta t r s p}$ & $\mathrm{SP}^{c}$ rescue with $\operatorname{trsp} p^{t} \& \operatorname{trsp} p^{t} \mathrm{G} 37$ \\
\hline Conditional $\mathrm{KO}^{d}$ & $\Delta t r s p^{\prime}$ & $\begin{array}{l}\mathrm{KO}^{d} \text { trsp in various tissues and } \\
\text { organs using promoters that are } \\
\text { tissue and organ specific }\end{array}$ \\
\hline $\begin{array}{l}\text { Transgenic/ } \\
\text { standard } \\
\mathrm{KO}^{d}\end{array}$ & $\begin{array}{c}\text { trsp } p^{t} / \Delta t r s p \\
\text { G37trsp } p^{t} / \Delta t r s p\end{array}$ & $\begin{array}{c}\mathrm{SP}^{c} \text { rescue in } \mathrm{KO}^{d} \text { mice }[6,7] \\
\text { Partial } \mathrm{SP}^{c} \text { rescue in } \mathrm{KO}^{d} \text { mice }[6,7]\end{array}$ \\
\hline $\begin{array}{c}\text { Transgenic/ } \\
\text { conditional } \mathrm{KO}^{d} \\
\text { (liver) }\end{array}$ & $\begin{array}{c}\text { trsp } p^{t} / \Delta t r s p^{l t} \\
\text { G37trsp } p^{t} / \Delta t r s p^{f}\end{array}$ & $\begin{array}{l}\mathrm{SP}^{c} \text { replacement in liver } \\
\mathrm{SP}^{c} \text { replacement in liver }\end{array}$ \\
\hline
\end{tabular}

${ }^{a}$ Genotype designations used for mouse models (see text).

${ }^{b}$ Uses - the various uses of the mouse models with accompanying references (see also text).

${ }^{c} \mathrm{SP}$ - selenoprotein(s).

${ }^{d} \mathrm{KO}$ - knockout.

${ }^{e}$ AM Diamond, personal communication.

${ }^{f_{R}}$ Irons, BA Carlson, DL Hatfield, C Davis, submitted.

${ }^{g}$ BA Carlson, ME Moustafa, R Shrimali, M Rao, N Zhong, S Wang, L Feigenbaum, BJ Lee,

VN Gladyshev and DL Hatfield, submitted. 
Initially, the resulting transgenic mice encoding multiple copies of $t r s p^{t}$ and G37trsp ${ }^{t}$ (see Table 1) were examined [8]. This study provided the first example of transgenic mice engineered to contain functional tRNA transgenes. The fact that over-expression of wild type Sec tRNA ${ }^{[\mathrm{Ser}] \mathrm{Sec}}$ due to the extra copies of $t r s p^{t}$ did not appear to influence selenoprotein synthesis in the organs and tissues examined suggested that the levels of the Sec tRNA $^{[\text {Ser]Sec }}$ isoforms were not limiting in protein synthesis (reviewed in $[4,5])$. However, mice carrying G37trsp $p^{t}$ had a pronounced effect on selenoprotein expression and the effect occurred in a protein- and tissuespecific manner [8]. The most and least affected selenoproteins were glutathione peroxidase $1(\mathrm{GPx} 1)$ and thioredoxin reductase 1 (TR1), respectively, and the organs which manifested the most and least affect on selenoprotein synthesis were liver and testes, respectively. The mutant Sec tRNA ${ }^{[\mathrm{Ser}] \mathrm{Sec}}$ product from G37trsp $p^{t}$ lacked the $\mathrm{i}^{6} \mathrm{~A}$ base modification and altered the levels of the two host Sec tRNA ${ }^{[\mathrm{Ser}] \mathrm{Sec}}$ isoforms is such a manner that the Um34 species was reduced and the $\mathrm{mcm}^{5} \mathrm{U}$ species was enriched. As the amount of the mutant tRNA increased with increasing numbers of transgenes, the amount of the Um34 species and the amount of some selenoproteins, and in particular, GPx1 also decreased. The correlation in reduction of the Um34 isoform and certain selenoproteins led us to propose that the Um34 modification is responsible for the expression of several selenoproteins that are involved in the lower echelon of selenoprotein hierarchy expression [5-7]. Interestingly, many of the selenoproteins that are expressed in the lower echelon of selenoprotein hierarchy and are sensitive to selenium status, such as GPx1, serve largely stress-related functions, while those that are expressed in the upper echelon of selenoprotein hierarchy and are less sensitive to selenium status, such as TR1, serve largely housekeeping functions. Those members associated with stress-related phenomena are the ones dependent on the Sec $\mathrm{tRNA}^{[\mathrm{Ser}] \mathrm{Sec}} \mathrm{Um} 34$ modification for their expression (see also Chapter 3 and [5-7]).

As shown in Table 1, the G37trsp $p^{t}$ mice have been used in several different studies. The studies have shown that these mice, which are deficient in selenoproteins involved in stress-related phenomena, have an enhanced 1) skeletal muscle adaptation after synergist ablation and following exercise [9], 2) incidence of prostate malignancy when the mice also carry an oncogene directed to this tissue (see legend to Table 1), and 3) incidence of breast malignancy when the mice also carry an oncogene directed to this tissue (see legend to Table 1). In addition, we have observed that G37trsp $p^{t}$ mice a significantly greater number of azoxymethane (AOM)-induced aberrant crypt formations (preneoplastic lesions in the colon) than wild type mice ( $R$ Irons, BA Carlson, DL Hatfield and CD Davis, submitted). Supplementing the diets of the AOM treated G37trsp ${ }^{t}$ and wild type mice with 0.1 and $2.0 \mu \mathrm{g} / \mathrm{g}$ selenium significantly reduced the incidence of preneoplastic lesions in both 
mouse lines. These observations are the first to provide evidence that both selenoproteins and low molecular weight selenocompounds play a role in the cancer protective effects of selenium.

In another study involving Sec $\mathrm{tRNA} \mathrm{A}^{[\mathrm{Ser}] \mathrm{Sec}}$ mutant transgenic mice, we examined the effect of A34trsp ${ }^{t}$, which also lacked Um34, on selenoprotein synthesis (B.A. Carlson, M.E. Moustafa, R. Shrimali, M. Rao, N. Zhong, S. Wang, L. Feigenbaum, B.J. Lee, V.N. Gladyshev and D.L. Hatfield, submitted). The effects of A34trsp ${ }^{t}$ on down regulating stress-related selenoprotein expression were similar to those of G37trsp $p^{t}$. Since both these mutants lack Um34, these observations provided further evidence that Um34 is responsible governing the expression of those selenoproteins involved in stress-related phenomena.

\section{Transgenic/knockout mouse models}

Since the standard knockout of trsp is embryonic lethal $[9,11]$, it appeared that this mutant could not be used for further study of selenoprotein expression. However, we devised a means of rescuing selenoprotein expression by crossing heterozygous trsp knockout mice with homozygous trsp $^{t}$ transgenic mice and breeding the offspring to obtain a line of mice lacking trsp ( $\Delta t r s p)$ that was dependent on the $t r s p^{t}$ for survival [6,7]. One advantage of rescuing a knockout mouse with a wild type or mutant transgene is that the number of transgenes, and therefore, the levels of the corresponding gene product can be maintained at normal or elevated amounts depending on the transgene copy number. Rescuing with 20 copies of the wild type transgene enriched the Sec tRNA ${ }^{[\operatorname{Ser}] S e c}$ population several fold, but little or no effect on selenoprotein expression in various tissues or organs was observed [6,7]. These observations provided further evidence that Sec $\mathrm{tRNA}^{[\mathrm{Ser}] \mathrm{Sec}}$ is not limiting in selenoprotein biosynthesis (reviewed in $[4,5]$ ). Rescue of the $\Delta$ trsp mice with the mutant transgene, G37trspt afforded us with an opportunity of obtaining a mouse line with a mutant transgene wherein there is no background of host Sec tRNA ${ }^{[\mathrm{Ser}] \mathrm{Sec}}$ and selenoprotein expression is therefore totally dependent on the mutant tRNA. G37trsp yielded a tRNA that lacked two base modifications, $i^{6} \mathrm{~A} 37$ and Um34 (see above, Chapter 3 and $[6,10]$ ) and mice rescued with G37trsp $p^{t}$ lacked several selenoproteins including glutathione peroxidases 1 and 3, SelR and SelT $[6,7]$. Interestingly, we were not successful in rescuing selenoprotein synthesis in $\Delta$ trsp mice with A34trsp ${ }^{t}$ (see reference to Carlson et al above). As discussed in greater detail in Chapter 3, the novel regulation of several selenoproteins involved in stress-related functions occurs at the level of translation. 


\section{Conditional knockout mouse models}

Removal of trsp from the mouse genome is embryonic lethal $[9,11]$ which prevented further study of the standard trsp knockout per se in selenoprotein expression. We therefore prepared the conditional knockout of trsp using loxP-Cre technology [9]. The removal of floxed trsp in mouse mammary epithelium [9] and in liver hepatocytes [12] was examined. trsp was targeted for removal in mammary epithelium using transgenic mice carrying the Cre recombinase gene under the control of the mouse mammary tumor virus long terminal repeat promoter or the whey acidic protein promoter. Neither Cre promoter was effective in complete removal of trsp in mammary epithelial cells, but the Sec tRNA ${ }^{[\mathrm{Ser}] \mathrm{Sec}}$ population was substantially reduced to alter selenoprotein expression in a protein specific manner [9]. In liver, however, the targeted removal of floxed trsp with transgenic mice carrying the Cre recombinase under the control of the albumin promoter was virtually complete [12]. Surprisingly, the mice survived without selenoprotein expression in hepatocytes which comprise about $85 \%$ of the liver cell mass. Selenoprotein P (SelP), which is the only known selenoprotein with multiple Sec residues (see Chapters 9,10 and 21 ), would seem to be largely made in the liver and transported to other organs and tissues as its level was reduced about $75 \%$ in plasma of the selenoproteinless liver knockout mice. These mice appeared phenotypically normal until about 24 hours before death and death appeared to be due to severe hepatocellular degeneration and necrosis with concomitant necrosis of peritoneal and retroperitoneal fat [52]. Although most animals lacking selenoprotein expression in their liver died within two to three months in this initial study, these animals may be kept alive for extended periods of time on a diet enriched in other nutrients (U. Schweizer, L. Schomburg and J. Kohrle, personal communication). This is an important observation since these animals live much longer on a different diet and can be subjected to various environmental agents to study the role of selenoproteins in liver function and health.

As selenium has been implicated in heart disease (see Chapter 25) and immune function (Chapter 27), we examined the role of selenoproteins in cardiovascular disease and the immune system. By targeting the removal of trsp in either endothelial cells or myocytes in skeletal and heart muscle, we have elucidated the role of selenoproteins in cardiovascular disease ( $R$. Shrimali, J.A. Weaver, G.R. Miller, B.A. Carlson, S.V. Novoselov, E. Kumaraswamy, V.N. Gladyshev and D.L. Hatfield, submitted). Removal of selenoprotein expression in endothelial cells was embryonic lethal. 14.5-dayold embryos had numerous abnormalities including necrosis of the central nervous system, subcutaneous hemorrhage and erythrocyte immaturity. Loss of selenoprotein expression in myocytes, however, manifested no apparent phenotype until about day 12 after birth, when affected mice developed decreased mobility and an increased respiratory rate, followed by death 
within a few hours. Although there was no evidence of inflammation of the skeletal muscle in mice that lacked trsp in myocytes, they had moderate to severe myocarditis with inflammation extending into the mediastinum.. Targeted removal of trsp in endothelial cells demonstrated an essential role of selenoproteins in their development, while targeted removal of trsp in myocytes demonstrated an essential role of selenoproteins in proper function of cardiac muscle. These studies also showed a direct connection between the loss of selenoprotein expression and cardiovascular disease (R. Shrimali, J.A. Weaver, G.R. Miller, B.A. Carlson, S.V. Novoselov, E. Kumaraswamy, V.N. Gladyshev and D.L. Hatfield, submitted).

The conditional knockout of trsp is an important mouse model as it provides a means of elucidating the roles of selenoproteins in health, development and/or function in tissues or organs for which there is a specific promoter. Promoters that function to express Cre early in development of a specific tissue or organ can be used to assess the role of selenoproteins in development of that tissue or organ. On the other hand, promoters that function to express Cre after the tissue or organ is developed can be used to assess the role of selenoproteins in proper function of that organ or tissue. Furthermore, promoters that function to express Cre either early or late in development of a specific tissue or organ, and provided the animal survives for a long period of time following trsp knockout, can be used to examine the animal's ability to handle various forms of stress (e.g., viral or bacterial infection, carcinogen(s), cancer driver gene(s), etc). Those animals that survive for long periods of time, while lacking selenoprotein expression in a specific tissue or organ, can also be used to assess the role of small molecular weight selenocompounds in health. Therefore, the conditional knockout of trsp in specific tissues and organs is an important tool for assessing the role of selenoproteins in health and development and this model can also be used to assess the role of small molecular weight selenocompounds in protecting the animal against environmental stresses.

\section{Transgenic/conditional knockout mouse models}

Although the rescue of mice encoding a $\Delta$ trsp mice with G37trsp provides a novel model for studying the role of housekeeping and stress-related selenoproteins in health and the role of the two Sec tRNA ${ }^{[\mathrm{Ser}] \mathrm{Sec}}$ isoforms in governing selenoprotein expression [6,7], this mouse model permit us to focus on the animal as a whole and not on not on the roles of these components in individual organs and tissues. However, removal of selenoprotein expression by targeting floxed trsp with a specific promoter Cre and replacing selenoprotein expression with a mutant trsp $^{t}$ permits us to assess the role of housekeeping and stress-related selenoproteins, as well as the role of both isoforms, in health and/or proper function of specific organs or tissues. Selenoprotein removal was targeted in liver of the floxed trsp 
mouse using the albumin Cre promoter and selenoprotein expression was replace with either G37trsp ${ }^{t}$ or A34trsp $p^{t}$ (B.A. Carlson, M.E. Moustafa, R. Shrimali, M. Rao, N. Zhong, S. Wang, L. Feigenbaum, B.J. Lee, V.N. Gladyshev and D.L. Hatfield, submitted). The pattern of replacing selenoprotein expression, wherein several selenoproteins associated with stress were not recovered, was similar with either the G37 and A34 mutant transgenes. The fact that the two mutant Sec tRNA ${ }^{[\mathrm{Ser}] \mathrm{Sec}}$ isoforms govern selenoprotein expression in virtually an identical manner without the influence of host wild type Sec tRNA ${ }^{[\mathrm{Ser}] \mathrm{Sec}}$ demonstrates that $\mathrm{Um} 34$ is responsible for the synthesis of stress-related selenoproteins.

Importantly, this mouse model will most certainly provide insights into one of the central questions in the selenium field which is "What are the contribution of selenoproteins versus low molecular weight selenocompounds in the cancer chemopreventive effects of selenium and other health benefits of this trace element?" Both these mutant transgenes replaced housekeeping selenoprotein expression, but not stress-related selenoprotein expression.

\section{Acknowledgements}

This work was supported by the Intramural Research Program of the National Institutes of Health, National Cancer Institute, Center for Cancer Research.

\section{References}

1. LC Clark et al 1996 JAMA 276:1957

2. http://www.crab.org/select/

3. http://www.cancer.gov/clinicaltrials/ft-ECOG-5597

4. DL Hatfield, VN Gladyshev $2002 \mathrm{Mol}$ Cell Biol 22:3565

5. DL Hatfield, BA Carlson, XM Xu, H Mix, VN Gladyshev 2006 Prog Nucl Acids Res Mol Biol (In press)

6. BA Carlson, XM Xu, VN Gladyshev, DL Hatfield $2005 \mathrm{~J}$ Biol Chem 280:5542

7. BA Carlson, XM Xu, VN Gladyshev, DL Hatfield 2005 In Grosjean (Ed) Fine-Tuning of RNA Functions by Modification and Editing. Topics in Current Genetics Vol 12, $\mathrm{p} 431$

8. ME Moustafa, BA Carlson, MA El-Saadani, GV Kryukov, QA Sun, JW Harney, KE Hill, GF Combs, L Feigenbaum, DB Mansur, RF Burk, MJ Berry, AM Diamond, BJ Lee, VN Gladyshev, DL Hatfield $2001 \mathrm{Mol}$ Cell Biol 21:3840

9. TA Hornberger, TJ McLoughlin, JK Leszczynske, DD Armstrong, RR Jameson, PE Bowen, ES Hwang, H Hou, ME Moustafa, BA Carlson, DL Hatfield, AM Diamond, KA Esser 2003 J Nutrition 133:3091

10. E Kumaraswamy, BA Carlson, F Morgan, K Miyoshi, GW Robinson, D Su, S Wang, E Southon, L Tessarollo, BJ Lee, VN Gladyshev, L Hennighausen, DL Hatfield $2003 \mathrm{Mol}$ Cell Biol 23:1477

11. LK Kim, T Matsufuji, S Matsufuji, BA Carlson, SS Kim, DL Hatfield, BJ Lee. 2000 RNA 6:1306

12. MR Bosl, K Takaku, M Oshima, S Nishimura, MM Taketo 1997 Proc Natl Acad Sci USA 94:5531

13. BA Carlson, SV Novoselov, E Kumaraswamy, BJ Lee, MR Anver, VN Gladyshev, DL Hatfield $2004 \mathrm{~J}$ Biol Chem 279:8011 